\title{
JULIETA NÃO ESTÁ PRONTA PARA SER MONTECCHIO - A UNIÃO DAS FAMÍLIAS JURÍDICAS E A NECESSIDADE DE UMA NOVA METODOLOGIA DO DIREITO PREOCUPADA COM PRECEDENTES
}

\author{
JULIET IS NOT READY TO BE A MONTAGUE - THE UNION OF THE TWO \\ JURIDICAL SYSTEMS AND THE NEED OF A NEW METHODOLOGY OF LAW \\ FOCUSED ON PRECEDENTS
}

\begin{abstract}
Pedro Henrique Veiga Chrismann
Doutorando em Teoria do Estado e Direito Constitucional pela Pontifícia Universidade Católica do Rio de Janeiro. Professor Assistente no Instituto Brasileiro de Mercado de Capitais IBMEC-RJ. E-mail: pedrochrismann@gmail.com
\end{abstract}

Recebido em: 23/03/2014

Aprovado em: 11/04/2016

Doi: $10.5585 / \mathrm{rdb} . v 14 \mathrm{i} 6.114$

RESUMO: É recorrente na academia a afirmativa que as tradições do civil law e da common law estão se aproximando. No entanto, não é da cultura jurídica brasileira o estudo adequado dos precedentes. Como eles se formam, qual material normativo extrair deles, entre outras questões importantes, acabam sendo deixadas de lado em detrimento de uma análise mais focada em como analisar e interpretar os estatutos jurídicos. Isso acaba afetando a produção das decisões do judiciário, no sentido que os responsáveis não têm a preocupação de deixar claro os critérios utilizados para diferenciar aquele caso de outros tantos e sobre como futuros casos possam ser semelhantes e decididos de maneira semelhante. Tal união entre famílias jurídicas fica, portanto, prejudicada na medida que decisões judiciais de cortes superiores cada vez mais influenciam julgamentos de juízes de comarcas inferiores. Pode-se, ou deveria ser possível de se, extrair uma norma de estrutura semelhante a de uma regra de um julgado de uma corte. Essa norma deveria ditar como juízes ou tribunais podem ou devem se comportar no futuro diante um caso de propriedades semelhantes. Faz-se necessária uma mudança de atitude da academia em se preocupar mais com questões procedimentais e empíricas; e das cortes superiores, em especial o Supremo Tribunal Federal, em utilizar técnicas que deixem claro o que pretendem deixar como precedentes.

Palavras-Chave: Regras; Precedentes; Supremo Tribunal Federal.

\begin{abstract}
It is recurrent in the academia the claim that civil law and common law systems are getting closer. Culturally, though, we don't study properly in Brazilian Law Schools how precedents are used. How they are made, which normative material extract from them, and other important questions, are left aside to the detriment of a analysis more focused on analyzing and interpreting statutes. This ends up affecting judicial rulings in the sense that the responsible for the decision don't have the preoccupation of clarifying the criteria they have used to differentiate the case in question from others and the criteria to hold a future case as similar and rule it in the same way. Such union between systems gets harmed given that judicial decisions from higher courts increasingly influence rulings made by judges from inferior courts. We can, or at least we should be able to, extract a norm with a similar structure to a rule from a ruling. This norm should be able to dictate how judges and courts can and should behave in the future when facing
\end{abstract}


a case with similar properties. A change in attitude is necessary both from academia - that should focus on procedimental and empirical questions - and from higher courts, especially the Supreme Court, in leave it clear what they intend to be understood as precedents from inferior courts.

Keywords: Rules; Precedents; Brazilian Supreme Court.

SUMÁRIO: Introdução; 1. Um gosto especial por regras; 2. Traduzindo decisões em normas (que se parecem com regras); 3. O Supremo Tribunal Federal e certo desleixo com os precedentes; Conclusão; Bibliografia; Sítios virtuais.

"Belo Montecchio, é certo: estou perdida, louca de amor; daí poder pensares que meu procedimento é assaz leviano; mas podeis crer-me, cavalheiro, que hei de mais fiel mostrar-me do que quantas têm bastante astúcia para serem cautas. Poderia ter sido mais prudente, preciso confessá-lo, se não fosse teres ouvido sem que eu percebesse, minha veraz paixão. Assim, perdoa-me, não imputando à leviandade, nunca, meu abandono pronto, descoberto tão facilmente pela noite escura."

(William Shakespeare)

\section{INTRODUÇÃO}

A tragédia mais famosa da história literária talvez seja a história de Romeu e Julieta, escrita por William Shakespeare. Tal peça ficou marcada pela morte por amor - de forma quase cômica - de dois adolescentes apaixonados, porém de famílias rivais. Embora seja esse o resumo que tenha ficado gravado para todos, a estória não termina nesse momento. $\mathrm{O}$ poeta inglês a finaliza com a união e o estabelecimento da paz por parte dos Montecchios e Capuletos. O enredo da presente história tema deste trabalho também envolve a união de duas famílias, de duas tradições, a do civil law e a do common law. No caso em tela, há diferenças e não rivalidade entre elas. Todavia, isso não significa que não se possa tirar qualquer lição do texto do Bardo. $\mathrm{O}$ romance dos jovens é tão arrematador quanto imprudente, e seu fỉm trágico é consequência do agir incauto de Julieta, que segue um plano mirabolante de Frei Lourenço. É essa necessidade de prudência, de cautela, que inspira o corrente texto. Trata-se de ter certo ceticismo - que faltou ao Frei - para possibilitar a união, em paz, das duas famílias.

A história aqui começa nas primeiras lições de Introdução ao Estudo do Direito, uma das matérias inaugurais do curso de graduação em Direito. Ensina-se sobre as diferenças entre as tradições do common law e do civil law. É explicado que os países da família do common law tem no uso dos costumes e, principalmente, nos precedentes judiciais as fontes principais do direito. Já o civil law é descrito como um sistema mais burocrático, que tem como principal fonte as leis, os códigos normativos escritos.

As aulas em História do Direito, outra das matérias propedêuticas apresentadas ao recém universitário, reforçam esse entendimento e explicam que o motivo dessas diferenças está na evolução natural do sistema preferido por cada país. Os ingleses, fundadores da tradição do common law não cultivavam a tradição de promulgar documentos normativos escritos e passaram esse costume aos países que colonizaram. Por outro lado, quando o civil law é apresentado há um regresso ao Código de Hamurabi, passando pela Codificação de Justiniano e ao Código Civil 
Napoleônico para demonstrar que essa simplesmente é uma tradição dos países europeus que colonizaram boa parte do mundo. ${ }^{1}$

Essas informações são levemente mitigadas quando se aprende, geralmente bem mais à frente no curso, que a tendência é a união entre as duas tradições, no sentido que o common law está cada vez utilizando mais textos normativos de legislaturas em detrimento dos precedentes, enquanto os precedentes ganham cada vez mais importância para o civil law. Porém, parece que o "estrago" já foi feito e algumas consequências surgem dele.

Em primeiro lugar, as leis, sobretudo aquelas formuladas na estrutura de regras, acabam ocupando um lugar especial no imaginário coletivo. As pessoas preferem trabalhar com regras. Esse fato é constatável pela observação da atuação de órgãos que não tem originalmente a função de produzir normas fazendo-o como forma de melhorar a sua atuação. É esse o motivo das súmulas de consolidação do entendimento dos tribunais. É colocar na forma de regras as posições formuladas e mantidas por aqueles tribunais durante os anos. É transformar a análise de precedentes em uma análise de regras.

Em números, até o final do ano de 2013, o Supremo Tribunal Federal já havia editado um total de 736 enunciados de sua súmula; o Superior Tribunal de Justiça produziu 478 e o Tribunal Superior do Trabalho fez 434. Mais modestamente os Tribunais Regionais Federais enunciaram um total de 241 (dos quais 49 pelo TRF-1 ${ }^{a}$ Região, 39 pelo TRF-2 ${ }^{\text {a }}$ Região, 35 pelo TRF-3 $^{\text {a }}$ Região, 79 pelo TRF-4 ${ }^{\text {a }}$ Região e 19 pelo TRF-5 ${ }^{\text {a }}$ Região) $)^{2}$. Nos Tribunais de Justiça dos Estados as súmulas também estão presentes. O TJ-RS, por exemplo, já havia editado à época $42,{ }^{3}$ enquanto o TJ-PR $40,{ }^{4}$ o TJ-CE $32^{5}$ e o TJ-PB $41,{ }^{6}$ mas o campeão de enunciados é o TJ-RJ, que já possuía 284 em sua súmula. ${ }^{7}$

Embora as súmulas não sejam de observância obrigatória para os magistrados, elas são importantes como guias sobre como os tribunais provavelmente julgarão determinados assuntos. Mas, mais do que isso, para os magistrados que pretendem ser promovidos e atingirem a posição de Desembargador, nos tribunais de justiça estaduais, ou a de Juiz de Tribunal, nos tribunais federais, seguir o entendimento sumulado parece ser um grande negócio. Isso porque a Resolução do CNJ $\mathrm{n}^{\circ}$ 106, de 6 de abril de 2010, ${ }^{8}$ estabelece como um dos critérios para avaliação da qualidade das decisões proferidas pelos magistrados o respeito às súmulas dos Tribunais Superiores.

Art. $5^{\circ} \mathrm{Na}$ avaliação da qualidade das decisões proferidas serão levados em consideração:

\footnotetext{
${ }^{1}$ Essa explicação também está presente, como era de se esperar, em livros tradicionalmente indicados ao aluno que acaba de ingressar na faculdade, veja: "Ao lado dessa tradição, que exagera e exacerba o elemento legislativo, temos a tradição dos povos anglo-saxões, nos quais o Direito se revela muito mais pelos usos e costumes e pela jurisdição do que pelo trabalho abstrato e genérico dos parlamentos. Trata-se, mais propriamente, de um Direito misto, costumeiro e jurisprudencial. Se, na Inglaterra, há necessidade de saber-se o que é lícito em matéria civil ou comercial, não há um Código de Comércio ou Civil que o diga, através de um ato de manifestação legislativa. O Direito é, ao contrário, coordenado e consolidado em precedentes judiciais, isto é, segundo uma série de decisões baseadas em usos e costumes prévios. Já o Direito em vigor nas Nações latinas e latino-americanas, assim como também na restante Europa continental, funda-se, primordialmente, em enunciados normativos elaborados através de órgãos legislativos próprios." In. Reale, Miguel. Lições preliminares de direito. São Paulo: Saraiva, 2006. p. 142

${ }^{2}$ Informação disponível em: http://www2.trf2.gov.br/NXT/gateway.dll?f=templates\&fn=default.htm\&vid=base_jud:v_sum

${ }^{3} \mathrm{http} / / / \mathrm{www} . t j \mathrm{rs} . j u s . b r /$ site/jurisprudencia/sumulas/sumulas_do_tribunal_de_justica/

${ }^{4}$ Ver http://www.tjpr.jus.br/jurisprudencia-sumulas

${ }^{5}$ Ver http://www.tjce.jus.br/consultas/consultas_sumulas.asp

${ }^{6}$ Ver http://www.tjpb.jus.br/portal/page/portal/tj/home/consulta_sumulas?p_id=79

${ }^{7}$ Ver http://webfarm.tjrj.jus.br/biblioteca/asp/textos_main.asp?codigo=150637\&desc=ti\&servidor=1\&iIdioma=0

${ }^{8}$ Disponível em: http://www.amb.com.br/docs/noticias/2010/CNJcriterio.pdf
} 


\section{(...)}

d) a pertinência de doutrina e jurisprudência, quando citadas;

e) o respeito às súmulas do Supremo Tribunal Federal e dos Tribunais Superiores.

Art. $10 \mathrm{Na}$ avaliação do merecimento não serão utilizados critérios que venham atentar contra a independência funcional e a liberdade de convencimento do magistrado, tais como índices de reformas de decisões.

Parágrafo único. A disciplina judiciaria do magistrado, aplicando a jurisprudência sumulada do Supremo Tribunal Federal e dos Tribunais Superiores, com registro de eventual ressalva de entendimento, constitui elemento a ser valorizado para efeito de merecimento, nos termos do princípio da responsabilidade institucional, insculpido no Código Ibero-Americano de Ética Judicial (2006).

Além disso, as súmulas permitem que os magistrados decidam de forma mais rápida uma vez que possibilitam que não se faça reflexões muito aprofundadas sobre cada caso. Isto é, se eles não se importarem em seguir as decisões prévias dos tribunais aos quais estão vinculados (ou do STF, ou de algum dos Tribunais Superiores), o que parece ser o caso mais comum. No entanto, ainda que não queiram seguir aquilo que seus colegas já fixaram, o ganho em celeridade pode ser mais um argumento em favor do cumprimento do entendimento sumulado para aquele que pretende ascender na carreira, já que conforme o previsto pela Resolução $n^{\circ} 106$ :

Art. $6^{\circ} \mathrm{Na}$ avaliação da produtividade serão considerados os atos praticados pelo magistrado no exercício profissional, levando-se em conta os seguintes parâmetros:

(...)

II - Volume de produção, mensurado pelo:

(...)

d) número de sentenças proferidas, por classe processual e com priorização dos processos mais antigos;

(...)

f) o tempo médio do processo na Vara.

Art. $7^{\circ}$ A presteza deve ser avaliada nos seguintes aspectos:

(...)

II - celeridade na prestação jurisdicional(...)

Como visto, embora não possuam o status e a obrigatoriedade de cumprimento das regras jurídicas, as súmulas têm não só a estrutura de regra como certa força normativa. Essa força normativa "emprestada" às súmulas reforça a alegação de que as pessoas preferem trabalhar com regras, ou que elas acreditam que a utilização delas possa ser algo positivo.

O problema é que não só as súmulas são utilizadas como jurisprudência, mas as decisões em sentenças ou acórdãos também o são. Aqui aparece a segunda consequência: Não se estuda como se dá o uso de precedentes. Como eles se formam, qual material normativo extrair deles, entre outras questões importantes, acabam sendo deixadas de lado em detrimento de uma análise mais focada em como analisar e interpretar os estatutos jurídicos. Isso acaba afetando a produção das decisões do judiciário, no sentido que os responsáveis não têm o cuidado de se deixar claro os critérios utilizados para diferenciar aquele caso de outros tantos e sobre como futuros casos possam ser semelhantes e decididos de maneira semelhante. Em suma, não há a preocupação em se deixar claro qual é a norma a ser extraída daquele julgado.

Nos países da common law, onde a decisão que serve de precedente o faz devido a autoridade de sua fonte e não em função da solidez de seu raciocínio, nem da convicção por parte 
do tribunal atual, de que o resultado indicado pelo precedente estava certo. ${ }^{9}$ Embora no Brasil não seja assim, não haja tamanha força normativa, as decisões anteriores são utilizadas aqui como precedentes no sentido de guias, conselhos sobre como agir no futuro. Isso é uma prática comum, especialmente com base nas decisões proferidas pelo STF para habeas corpus ou em sede difusa de controle de constitucionalidade, e por esse motivo se deveria ter mais cuidado em se deixar claro as peculiaridades do caso em questão e a relação delas com a decisão. ${ }^{10}$

O objetivo desse trabalho é de melhor entender as consequências da falta de um estudo acurado sobre os precedentes. Não há pretensão de se esgotar o tema, mas apenas de tentar buscar um maior entendimento $\mathrm{O}$ conjunto de hipóteses é o seguinte: Pode-se, ou deveria ser possível de, extrair uma norma de estrutura semelhante a de uma regra de um julgado. Essa norma deveria ditar como juízes ou tribunais podem ou devem se comportar no futuro diante um caso de propriedades semelhantes. Esses julgados geralmente surgem e se tornam paradigmáticos quando os julgadores tratam regras de forma particularista ou resolvem problemas de indeterminação delas. Os tribunais e, especialmente, o Supremo Tribunal Federal não tem tido o cuidado de deixar explícita a norma que pretende servir como precedente e isso é um problema.

Para isso, o trabalho será dividido em três partes. Inicialmente será esboçado como regras funcionam, alguns de seus problemas e formas diferentes de se lidar com eles. Posteriormente, será demonstrado, de forma breve, como se extrair uma norma de um precedente. A parte final irá se ocupar com alguns exemplos de casos em que o Supremo Tribunal Federal não teve o cuidado de expressar os critérios que deveriam ser levados em conta no futuro caso alguém quisesse seguir um daqueles julgados, utilizando-o como precedente. A partir dessa exposição poderá ser feita a conclusão de que o Tribunal mais importante do país deveria se preocupar com métodos de exposição de argumentos que sejam acessíveis de forma clara no futuro.

\section{UM GOSTO ESPECIAL POR REGRAS}

Falou-se que a tradição da civil law trabalha com textos normativos abstratos e que a maioria desses textos tem a estrutura de regras. Ainda, que parece ser o caso que as pessoas desse sistema preferem trabalhar com esse tipo de instrumento, dando-se o exemplo da construção de súmulas de tribunais, na forma de regras, para facilitar a vida daqueles que buscam o entendimento consolidado sobre alguns assuntos daquela corte. $\mathrm{O}$ que não foi falado, no entanto, é sobre o quê são essas regras, como identificar essa estrutura comum a elas e como elas funcionam.

Schauer define as regras prescritivas como passíveis de serem escritas sob o modelo "Se x então y". Observa-se a presença de uma parte que indica o alcance normativo, as condições fáticas que possibilitam a aplicação da regra, ou como Schauerdefine: o predicado fático, termo

\footnotetext{
${ }^{9}$ Schafer, Frederick. Thinking like a Lawyer: a New Introduction to Legal Reasoning. Oxford University Press, 2009. p. 41

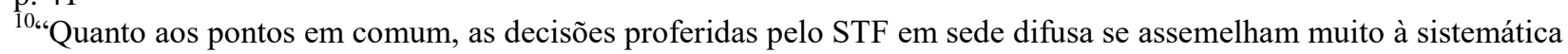
do judge made law: referem-se a um litígio entre partes e geram, além de um dispositivo concreto, que soluciona a lide, uma exegese geral sobre a questão constitucional. Tal identidade é compreensível, na medida em que esta via de controle de constitucionalidade se inspirou no direito norte-americano. Por outro lado, apresenta limites: os julgados produzidos em sede incidental não são dotados de efeitos normativos, ao menos por enquanto, (...) e, nos tribunais, há um fracionamento entre o órgão competente para apreciar a inconstitucionalidade da lei (art. 481, CPC)". In. Mello, Patrícia Perrone Campos. Precedentes - $O$ desenvolvimento judicial do direito no constitucionalismo contemporâneo. Rio de Janeiro: Renovar, 2008. p. 145.
} 
adotado aqui. ${ }^{11} \mathrm{O}$ predicado fático corresponde ao ' $\mathrm{x}$ ' de 'Se x', como em: "Se alguém pisar a grama, deve ser advertido." Ele apresenta uma condição necessária e suficiente para que a regra seja aplicada. A outra parte das regras é o consequente, que prescreve o que deverá ocorrer quando se verifiquem as condições especificadas pelo predicado fático. É o consequente que define se o predicado fático deve ser tratado como uma permissão, proibição ou obrigação. No exemplo anterior, corresponderá a parte de se aplicar a advertência.

No entanto, as regras nem sempre são apresentadas em um formato em que a separação entre suas partes possa ser feita de forma nítida. De todo modo, qualquer regra pode ser reescrita de forma a esclarecer a parte que esteja obscura. A regra formulada da seguinte forma " $E$ proibida a venda de cocos nas praias do Rio de Janeiro" pode ser reescrita como "A venda de cocos nas praias do Rio de Janeiro é passível de punição de advertência ou multa".

Uma vez separado o consequente do predicado fático, observa-se a presença de uma generalização na hipótese. Pode-se dizer que é justamente esse o ponto que diferencia uma regra de uma ordem. Ao dizer: "Noel, não pise a grama!", está sendo proferida uma ordem, isto é, uma instrução de proibição a um particular em dado momento. Diferentemente do caso de "É proibido pisar a grama". Mesmo que se tratasse de uma generalização mais específica como: "É proibido a professores de filosofia do direito, que usem óculos e tenham sardas, pisar a grama", ainda assim seria uma regra, dada a aplicabilidade de seu conteúdo, de sua proibição, a toda uma classe.

O que impulsiona a generalização prescritiva é a observação da presença de propriedades causalmente relacionadas à justificação. O predicado fático é, portanto, uma generalização de propriedades percebidas como indesejadas pela justificação. Observando-se, portanto, a presença da propriedade causalmente relacionada à justificação em um indivíduo, como representante de um grupo maior, generaliza-se. Ou seja, se o que se pretende, por exemplo, é manter um ambiente limpo e silencioso, e ao se observar o comportamento de um cachorro de cor negra, cujo dono é o sujeito 'A', sujando e latindo alto, busca-se qual a propriedade presente nesse indivíduo que o torna desagradável. Empiricamente sabe-se que a cor ou o dono do cão não são o que se liga diretamente à justificação, ou seja, não existe um nexo causal probabilístico entre tais fatores e a conduta indesejada, mas o fato de ser um cão. Uma regra que proíba a entrada de "negros", ou de coisas pertencentes ao sujeito 'A'. Logo, proíbe-se a entrada de cachorros, e não de indivíduos de cor negra ou de cães do dono 'A' Mesmo porque, a proibição exclusiva de cachorros do dono ' $A$ ' não acabaria totalmente com o problema, não satisfaria inteiramente à justificação.

Logo, o predicado fático se apresenta como um conjunto de fatos. Ele indica um aumento da possibilidade de ocorrência daquilo que se busca alcançar pela justificação da regra. No entanto, apenas uma possibilidade de ocorrência acaba por gerar algumas distorções normativas, como indica Schauer:

Por serem as generalizações necessariamente seletivas, generalizações probabilísticas irão incluir algumas propriedades que em casos particulares serão irrelevantes, e todas as generalizações, probabilísticas ou não, irão excluir algumas propriedades que em casos particulares serão relevantes. $\mathrm{O}$ predicado fático irá, portanto, por vezes, acionar características do caso que não servem à justificação da regra, e em outros falhará no reconhecimento de características do caso cujo reconhecimento iria servir à justificação da regra ${ }^{12}$. (Tradução nossa)

\footnotetext{
${ }^{11}$ Schauer, Frederick. Playing By the Rules: A Philosophical Examination of Rule-Based Decision-Making in Law and in Life. Oxford University Press, 1998. p. 22.

${ }^{12}$ No original: "Because generalizations are necessarily selective, probabilistic generalizations will include some properties that will in particular cases be irrelevant, and all generalizations, whether probabilistic or not, will exclude

Revista de Direito Brasileira | São Paulo, SP | v. 14 | n. 6 | p. 3 - 17 | maio/ago. 2016
} 
Fala-se em sobre-inclusão para designar o problema no qual o predicado fático compreende um estado de fatos que em situações particulares não produziriam a consequência descrita pela justificação da regra, ainda que façam parte da escolha probabilística da generalização. Melhor explicando, quando a regra inclui mais casos do que a sua justificação exigiria, ou seja, inclui mais particulares dentro de um escopo de permissão ou proibição do que o necessário para a satisfação da justificação da regra. À título de exemplo pode-se imaginar que um restaurante estabeleça a regra "É proibida a entrada de animais". A justificação dessa regra é baseada em experiência do dono do estabelecimento com cães, que, antes da regra ser posta, entravam, sujavam, latiam e atrapalhavam o movimento dos garçons pelas mesas. Ora, alguns cães podem não se comportar de forma a sujar, latir ou atrapalhar qualquer movimento, pode se imaginar um cão pequeno que fique dormindo dentro da bolsa de uma senhora. Ou ainda, um cão guia, ou um cão policial, ambos adestrados da melhor forma possível. Ainda, pode-sepensar em outros animais, como os gatos, que podem não sujar o ambiente e podem ainda ser apreciados pelos presentes, como ocorre no caso dos "Cafés de Gatos" no Japão.

A sub-inclusão ocorre no sentido inverso, ou seja, ela ocorre quando o predicado fático de uma regra não abarca situações que produziriam a consequência prevista pela justificação. A regra não inclui casos que seriam pertinentes à justificação. Peguemos como exemplo a regra que proíbe o consumo de bebidas alcoólicas para menores de 18 anos. Se a justificação dessa regra é relacionada a evitar um comportamento irresponsável, claramente podemos perceber que alguns maiores de 18 anos também poderiam comportar-se inadequadamente ao beber. Ou ainda, uma regra que proíba o consumo de qualquer substância alcoólica antes de se dirigir um automóvel, cuja justificativa seja a diminuição dos acidentes de trânsito causados por motoristas entorpecidos, exclui a possibilidade de um usuário de drogas ilícitas dirigir um automóvel logo após consumi-las.

Note-se que esses dois problemas são oriundos da determinação das regras. Outro problema diferente é justamente quando um termo presente na regra é indeterminado, ou seja, quando há a presença de conceitos vagos no texto da regra. Nesse caso, não se sabe se o caso em questão tem as propriedades necessárias para ser enquadrado dentro do escopo da regra, ou não. Vale a pena a leitura de Struchiner, que aborda o assunto de forma profunda, mas didática, leiase:

Alguns conceitos, cuja correta aplicação depende da verificação de uma única propriedade, podem apresentar casos fronteiriços ou nebulosos quando não se sabe qual é o grau de presença da propriedade que se faz necessário para a aplicação do conceito. Por outro lado, alguns conceitos ou predicados são multidimensionais, o que quer dizer que o seu significado depende de uma série de propriedades constitutivas diferentes e da maneira como essas propriedades devem estar combinadas. Tais conceitos podem apresentar, além da vagueza de grau, uma vagueza combinatória. A vagueza combinatória se refere à imprecisão a respeito de quais são as propriedades constitutivas de um conceito e à maneira pela qual essas propriedades devem estar combinadas para que o uso do termo geral possa ser empregado de forma legítima. Hart utiliza como exemplo de vagueza de grau o predicado "careca" e como exemplo de vagueza combinatória o "jogo de xadrez" (...) De acordo com ele, existe uma zona de penumbra na qual não é possível dizer ao certo se uma pessoa é ou não um careca. Afinal, quantos fios de cabelo alguém tem que perder para ser um careca? Hart

some properties that will in particular cases be relevant. Factual predicate will therefore in some cases turn on features of the case that do not serve the rule-se justification, and in others fail to recognize features of the case whose recognition would serve the rules justification." Idem p. 33 
questiona se um jogo de xadrez pode ser chamado de "xadrez" mesmo quando jogado sem a peça da rainha. Trata-se de uma vagueza combinatória: o caso paradigmático do jogo de xadrez é um complexo formado por elementos distintos e não sabemos exatamente qual desses elementos ou combinação de elementos é necessária para que o termo "xadrez" possa ser empregado. ${ }^{13}$

As regras, portanto, podem ter problemas de indeterminação e outros causados por sua determinação. O julgador pode não só se deparar com casos em que tem de decidir se um skate é um "veículo" para fins da regra "É proibida a entrada de veículos no parque", mas como deve se posicionar em casos em que a regra claramente deveria ser aplicada se a sua justificação fosse imediatamente cumprida em que, no entanto, a própria linguagem da regra aponta para um resultado diferente. É exatamente em casos nos quais alguns dilemas como esses aparecem que se torna importante a decisão do magistrado. Como resolver a questão que aparece não só diante dele, mas como resposta à sociedade para casos semelhantes futuros $?^{14}$

Parece óbvio que o problema vai ter uma ordem de grandeza seguindo a hierarquia institucional judiciaria. Dessa maneira, um julgado resolvendo uma questão controvertida sobre a melhor interpretação de um conceito presente em uma lei tem um efeito e um alcance muito maiores quando decididos pelo Supremo Tribunal Federal, ou pelo Superior Tribunal de Justiça, do que quando produzidos por um juiz de primeira instância de um tribunal estadual. Simplesmente há um maior foco nos tribunais superiores, há uma maior pressão por respostas e os casos realmente difíceis costumam ser decididos de fato por lá.

É por essa expectativa maior de resposta, por essa espera por um posicionamento diante a um problema normativo, que o Supremo Tribunal Federal foi escolhido como alvo desse estudo, como já foi dito. Mas antes de se adentrar na análise de alguns casos decididos por essa corte e a possibilidade de se retirar uma norma que regule o futuro dessas decisões, deve-se entender como é possível fazer tal extração.

\section{TRADUZINDO DECISÕES EM NORMAS (QUE SE PARECEM COM REGRAS)}

No dia em que completava quinze anos de idade, Andreia, aluna com currículo impecável, dedicada e que ainda ajuda com as tarefas em casa, ganha de seus pais uma viagem internacional. Seu irmão mais novo, João, observa o acontecimento e acredita que sendo um bom aluno e ajudando seus pais em casa também seria recompensado com o mesmo presente em seu aniversário de quinze anos. À época da celebração da data, João tem suas expectativas frustradas e ganha apenas uma camisa de seus pais.

\footnotetext{
${ }^{13}$ STRUCHINER, Noel. "Indeterminação e Objetividade: Quando o Direito diz o que não queremos ouvir" In. Ed. Ronaldo Porto Macedo Jr. e Catarina Helena Cortada Barbieri Direito e Interpretação - Racionalidades $e$ Instituições, São Paulo: Saraiva, 2011.p. 138.

${ }^{14}$ Algumas maneiras de lidar com regras sugeridas pela doutrina tendem a dar uma resposta a essa indagação. Para os casos de indeterminação, o critério sugerido por Hart é o da abordagem paradigmática e criteriológica, ou seja, elegese um caso paradigmático daquele conceito em questão e tenta-se estabelecer alguns critérios que tornam algo merecedor do mesmo rótulo. Para os casos de sub e sobre-inclusão, várias respostas surgem. Os formalistas, por exemplo, sugerem que o texto da norma sejam aplicados independente da análise de sua justificação. Eles acreditam que as regras só funcionam como regras quando são levadas a sério, ou seja, conseguem exercer uma pressão no raciocínio prático sem que sejam superadas a todo o tempo. Os particularistas, por outro lado, acreditam que regras funcionam como meras sugestões e que devem ser corrigidas a todo o tempo conforme os propósitos de sua justificação. Para uma leitura mais acurada, ver Struchiner, Noel. "O Direito como um campo de escolhas: por uma leitura das regras prescritivas como relações". In. Nas fronteiras do formalismo. São Paulo: Saraiva, 2010. p. 103127.
} 
João ficou decepcionado porque ele observou o caso de sua irmã e extraiu a seguinte norma: "Completando 15 anos, desde que seja um aluno exemplar e ajude nas tarefas domésticas, o filho ganhará uma viagem internacional". Ele se esforçou para ter notas até melhores as de Andreia e trabalhou tão duro quanto sua irmã em casa e, no entanto, não ganhou a viagem. Ele decide abordar seus pais então e perguntar o motivo de tamanha injustiça. A resposta dada a ele foi a de que ele tinha entendido errado. O motivo pelo qual a sua irmã ganhara a viagem foi tãosomente por ela ser uma menina e ter completado quinze anos de idade, data tradicionalmente considerada especial para as meninas. A regra que seus pais tinham em mente em verdade era: "Completando aniversário de anos idade tradicionalmente celebrada como especial, o filho ganhará uma viagem internacional”. Como para os homens o aniversário de dezoito anos de idade era considerado especial, João ganharia sua viagem quando atingisse essa data.

Essa anedota, dentre outras tantas formuladas pela doutrina quando tenta explicar o modo de operar do stare decidis no common law, ajuda a entender como os precedentes funcionam e, mais especificamente para a matéria que se está sendo discutida aqui, como é possível extrair normas em formato de regras (holding) de decisões. Mais ainda, sobre como é possível criar normas com base em suposições de quais foram os fatos relevantes quando não se está claro qual foi o critério adotado para chegar àquele resultado.

Os precedentes funcionam, como visto, por meio de raciocínios analógicos do tipo:

(1) casos $a, b, c \ldots$ e o caso em questão compartilham as propriedades $p, q, r \ldots$; (2) casos $a, b, c$ compartilham a propriedade de terem sido decididos em favor de X; portanto, (3) o caso em questão (ou algum assunto do caso em questão) deve ser decidido em favor de $X .^{15}$

O fundamento para esse tipo de funcionamento se dá em função de se tratar casos semelhantes de maneira semelhante, ideia que encontra suporte em valores como o de igualdade, segurança jurídica, previsibilidade, equidade e justiça. A dificuldade, no entanto, reside no fato de se encontrar as semelhanças necessárias e suficientes no caso anterior para que a mesma decisão possa ser tomada, uma vez que "o raciocínio analógico por si só não determina de forma clara como a semelhança entre casos deve ser estabelecida, apenas que se a semelhança for estabelecida os casos devem receber o mesmo tratamento."16

Schauer afirma que ao se entender o caso precedente como um conjunto de fatos e uma decisão, então o juiz ou a corte responsável pelo caso presente deverá construir, a partir de uma abstração (generalização), um predicado factual que englobe o caso precedente e o atual. Isso é necessário uma vez que o caso decidido falou apenas sobre um fato particular e não sobre uma categoria inteira.

Na decisão da corte inglesa, por exemplo, em Donoghue v. Stevenson, em que foi atribuída a responsabilidade civil a uma engarrafadora de cervejas pelo seu produto defeituoso, no caso em questão, pelo cliente ter encontrado como uma lesma em decomposição encontrada dentro da garrafa. É possível de se imaginar um caso subsequente em que é encontrada uma aranha numa garrafa de água gaseificada. Há a necessidade de se generalizar a partir do primeiro caso, uma vez que ele não falou sobre animais em decomposição em garrafas de bebida, mas

\footnotetext{
${ }^{15}$ White, Jefferson. "Analogical Reasoning” Apud Struchiner, Noel. Direito e Linguagem: Uma Análise da Textura Aberta da Linguagem e sua Aplicação ao Direito. Rio de Janeiro: Renovar, 2002. p. 45

${ }^{16}$ Struchiner, Noel. Direito e Linguagem: Uma Análise da Textura Aberta da Linguagem e sua Aplicação ao Direito. Rio de Janeiro: Renovar, 2002. p. 48.
} 
apenas sobre lesmas em decomposição dentro de garrafas de cerveja e não há obrigação lógica $a$ priori de se tratar de forma semelhante o caso da aranha na garrafa de água gaseificada. ${ }^{17}$

Essa não obrigação lógica significa que a corte presente não está "compelida de forma peremptória, a construir um único e determinado predicado factual que se segue logicamente do conjunto de fatos e da decisão do caso precedente." 18 Isso quer dizer que partindo de um conjunto de fatos e uma decisão pode-se extrair uma lista de inúmeros predicados factuais. Ou seja, mais de uma regra pode ser estabelecida com base em generalizações, basta que diferentes características sejam consideradas relevantes para aquele que está formulando o enunciado. ${ }^{19}$

Durante anos foram construídas inúmeras maneiras de se tentar solucionar esse problema, cada uma com o seu devido critério e mérito. Uma vez ser ainda uma questão que gera perplexidade para a doutrina, e por não ser o tema específico desse trabalho, não cabe aqui explorá-las. $^{20}$

O mais importante é que quando se tem regras claras o problema da escolhe das propriedades relevantes para a generalização já foi resolvido. Tendo em vista que os tribunais inferiores devem respeito aos precedentes dos tribunais superiores no direito de países da common law é desejável que as cortes mais altas estabeleçam, portanto, a regra, para que se possa garantir aquilo a que os precedentes devem servir, que são aqueles valores que foram apontados aqui, como segurança jurídica, previsibilidade e igualdade de tratamento, leia-se:

O tribunal afirma a regra de direito na qual baseia sua decisão, aplica essa regra aos fatos diante de si, e proclama um resultado. E isso é o holding. Os problemas começam quando um tribunal não diz explicitamente qual é o seu holding, e deixa por conta dos leitores a tentativa de determiná-lo. Na perspectiva tradicional, isso pode ser feito por meio da combinação entre o relato judicial dos fatos relevantes e o resultado afirmado pelo tribunal, mas, pelos motivos vistos acima, isso é insatisfatório. Se o tribunal não diz por que os fatos relevantes são relevantes, tudo que nos resta é um relato dos fatos que pode ser interpretado em numerosos níveis de abstração. Ficamos sem nenhuma noção sólida de qual teria sido o entendimento do tribunal, e sem nenhuma maneira de aplicar a decisão precedente no futuro de forma confiável. Somente ao afirmar o seu holding é que o tribunal permite que tribunais subsequentes efetivamente se pautem por (e obedeçam a) seu holding, pois, sem essa declaração, o holding pode ser praticamente qualquer coisa. Mas, com essa declaração, e com nosso entendimento do papel central que ela cumpre na definição do holding, a própria

\footnotetext{
${ }^{17}$ Schauer, Frederick. Playing By the Rules: A Philosophical Examination of Rule-Based Decision-Making in Law and in Life. Oxford University Press, 1998. p. 183.

${ }^{18}$ Struchiner, Noel. Direito e Linguagem: Uma Análise da Textura Aberta da Linguagem e sua Aplicação ao Direito. Rio de Janeiro: Renovar, 2002. p. 50

${ }^{19}$ Da mesma maneira escreve Arthur José Faravet Cavalcanti: "Mas como identificar a ratio decidendi? Eis aí uma tarefa muitas vezes bastante difícil. Em regra ela não está expressamente formulada. E se porventura estivesse, de pouco adiantaria, pois seria lícito ao juiz do caso subsequente ver no julgado anterior uma ratio decidendi diversa da que este se houvesse atribuído. Por outro lado, uma decisão judicial lida com fatos. A ratio decidendi é, porém, uma formulação de caráter genérico. Para identificá-la é preciso, pois, passar do particular ao geral. Os mesmos fatos comportam, contudo, diferentes graus de generalização. Coloca-se, pois, a questão de determinar, dentre as diversas generalizações possíveis, a partir dos fatos considerados no julgado, qual delas é a ratio decidendi." In. A Estrutura Lógica do Direito. Rio de Janeiro: Renovar, 2003. p. 66.

${ }^{20}$ Patrícia Perrone cita alguns dos critérios levantados pela doutrina como, por exemplo, o uso de linguagem canônica, regras da cultura e da linguagem, paradigmas jurídicos e valorativos e a análise dos casos precedentes e subsequentes. In Precedentes - $O$ desenvolvimento judicial do direito no constitucionalismo contemporâneo. Rio de Janeiro: Renovar, 2008. pp. 132-135.
} 
ideia do que é um holding, assim como a ideia de ratio decidendi, torna-se bem menos misteriosa. ${ }^{21}$ (Tradução nossa)

Ainda que essa necessidade seja maior para aqueles que tem no precedente uma fonte oficial e principal do direito, essa clarificação parece ser importante também, e exatamente pelos mesmos motivos, quando em países de civil law julgadores buscam em decisões de cortes superiores ou dentro do próprio tribunal o fundamento para os seus próprios julgados.

\section{O SUPREMO TRIBUNAL FEDERAL E CERTO DESLEIXO COM OS PRECEDENTES}

Como já foi dito, parece ser o caso que o Supremo Tribunal Federal não tem muita preocupação com a questão sobre se seus julgados servirão como precedente no futuro, independente da formulação de súmulas (vinculantes ou não). Oportuno agora demonstrar, de forma breve, alguns dos casos em que o Tribunal parece ter agido da maneira descrita.

A norma construída a partir do art. 224 do Código Penal, ao prever o crime de estupro, estabelece uma presunção incondicional de violência para o caso de a vítima ter idade inferior a 14 anos. Se for praticada uma relação sexual com menor de 14 anos, então deve ser presumida a violência por parte do autor. A norma não prevê qualquer exceção. (...) Mesmo assim, o Supremo Tribunal Federal, ao julgar um caso em que a vítima tinha 12 anos, atribuiu tamanha relevância a circunstâncias particulares não previstas pela norma, como a aquiescência da vítima ou a aparência física e mental de pessoa mais velha, que terminou por entender, preliminarmente, como não configurado o tipo penal, apesar de os requisitos normativos expressos estarem presentes. ${ }^{22}$

STF, $2^{\text {a }}$ Turma, HC 73.662-9 MG, rel. Min. Marco Aurélio, j. 21.5.1996, DJU 20.0.1996, p. 34.535.

O Supremo nesse caso, relatado de forma didática por Humberto Ávila, excepcionou a regra do Código Penal tendo em vista "circunstâncias particulares não previstas pela norma, como a aquiescência da vítima ou a aparência física e mental de pessoa mais velha", no entanto, não deixou de forma clara qual é a regra para o futuro. Ou seja, precisa ter 12 anos, ou pode ser menos? Precisa aparentar mais idade, mas quão mais velha precisa aparentar, 18 anos ou pelo menos mais que 14? O que significa aquiescência para uma criança? Existem outras circunstâncias peculiares não previstas pela norma e ausentes no caso, mas que deveriam ser respeitadas no futuro? Há uma imensa dificuldade em se colocar no formato de uma regra determinada todos os critérios levantados pelo Supremo.

A norma construída a partir do inciso II do art. 37 da Constituição Federal estabelece que a investidura em cargo ou emprego público depende de aprovação prévia em concurso público de provas ou de provas e títulos. Se for feita admissão de funcionário público, então essa investidura deverá ser precedida de concurso público; caso contrário essa investidura deverá ser declarada inválida. Além disso, o responsável pela contratação terá, conforme a lei, praticado ato de improbidade administrativa, com várias consequências, inclusive o ingresso da ação penal cabível. Mesmo assim, o Supremo Tribunal

\footnotetext{
${ }^{21}$ Schauer, Frederick. Thinking Like a Lawyer: A New Introduction to Legal Reasoning. Oxford University Press, 2009. p. 55

${ }^{22}$ Ávila, Humberto. Teoria dos Princípios - da definição à aplicação dos princípios jurídicos. $9^{\mathrm{a}}$ Edição. São Paulo: Malheiros, 2009. p. 45
}

Revista de Direito Brasileira | São Paulo, SP | v. 14 | n. 6 | p. 3 - 17 | maio/ago. 2016 
Federal deixou de dar seguimento à ação cabível ao julgar caso em que a prefeita de um Município foi denunciada porque, quando exercia a chefia do Poder Executivo Municipal, contratou sem concurso público um cidadão para a prestação de serviços como gari pelo período de nove meses. No julgamento do habeas corpus considerou-se inexistente qualquer prejuízo para o Município em decorrência desse caso isolado. Além disso, considerou-se atentatório à ordem natural das coisas, e, por conseguinte, ao princípio da razoabilidade, exigir a realização de concurso público para uma única admissão para o exercício de atividade de menor hierarquia. ${ }^{23}$

STF, 2 $2^{\text {a }}$ Turma, HC 77.003-4 PE, rel. Min. Marco Aurélio, j. 16.6.1998, DJU 11.9.1998, p.5.

Nessa última decisão, o STF parece ter ido um pouco melhor, mas continuou sendo obscuro quanto a seu critério decisional. Decidiu como "atentatório à ordem natural das coisas, e, por conseguinte, ao princípio da razoabilidade, exigir a realização de concurso público para uma única admissão para o exercício de atividade de menor hierarquia". Parece que a regra é: "Será realizado concurso público para admissão de servidor ou empregado público conforme o inciso II do art. 37 da Constituição Federal, exceto quando houver apenas uma admissão para o exercício de atividade de menor hierarquia." Não fica claro, no entanto, se a admissão pode ser para vários cargos de apenas uma vaga, ou apenas uma contratação por vez, e se por vez, quanto tempo depois pode contratar de novo? Uma única contratação é pelo período orçamentário ou por mês? $\mathrm{O}$ que deve ser considerado de menor hierarquia? Menor hierarquia dentro do quadro funcional de uma instituição ou há uma hierarquia dentro do quadro de serviços públicos em geral?

Por último, cabe a análise do HC n. 83.996, julgado pelo STF em 17.08.2004, impetrado em favor do diretor teatral Gerald Thomas. No caso, o diretor havia, diante a vaias do público para a sua peça, simulado o ato de masturbação e mostrado suas nádegas para a plateia presente. Havia sido detido, o diretor, por Ato obsceno (conforme art. 233 do Código Penal). No entanto, o STF decidiu pelo deferimento do HC num empate de votos, apoiando-se no voto de Gilmar Mendes que se utilizou de argumentos do tipo: Ainda que de mau gosto, tratava-se de um protesto, protegido pela liberdade de expressão; havia cena de masturbação durante a própria peça; o público era adulto, o ato ocorreu às duas horas da manhã, na cidade do Rio de Janeiro.

Pelo que foi construído até aqui, sobram dúvidas quanto a que tipo de norma poderia se extrair desse julgado. Precisa ser um protesto dentro de um teatro ou de algum lugar onde haja arte envolvida? A plateia precisa ser adulta? Precisa ser de madrugada e em uma cidade grande? A solução do STF, mais uma vez, preocupou-se muito em atingir o resultado mais justo para o caso concreto e muito pouco em deixar claro como atingir uma solução semelhantemente justa no futuro.

\section{CONCLUSÃO}

É claro que não se pode ter a intenção de representar a totalidade de casos que o Supremo Tribunal Federal julga com uma exposição de apenas alguns exemplares. Ainda assim,espera-se que ao longo desta exposição tenha ficado claro como é importante que o Supremo Tribunal Federal justifique se utilizando de construções em formatos de regras em suas decisões. As regras, apesar de subótimas, parecem ser instrumentos que simplificam as tomadas de decisão e isso parece ser desejável pelo sistema institucional brasileiro. Além disso, os precedentes são, sim, utilizados no Brasil como fundamento para condutas e decisões posteriores.

\footnotetext{
${ }^{23}$ Idem p. 46.
}

Revista de Direito Brasileira | São Paulo, SP | v. 14 | n. 6 | p. 3 - 17 | maio/ago. 2016 
Se há, portanto, como deixar claro a regra utilizada como fundamento para o caso em questão, isso deve ser feito.

Em primeiro lugar, no entanto, uma mea culpa é necessária. A tradição na academia jurídica brasileira tem sido a de se louvar os tribunais ou de criticá-los, buscando-se dar suporte futuro aos que operam o aparato jurídico. Sem querer apontar dedos, comumente tal busca se mostra impregnada de ideais políticos, quase sempre mascarados por termos nebulosos. Indicações na doutrina de que o direito deve ser "justo", "democrático", "respeitar os valores humanos", "emancipatório", entre tantos outros termos, são comuns e defender qualquer postura que não hasteie a bandeira de qualquer desses valores - ou que não pareça hastear - é considerado quase uma falha de caráter do acadêmico.

Adrian Vermeule, cuja linha de raciocínio vale a pena reproduzir, todavia afirma que as teorias de direito têm cometido alguns equívocos em suas preocupações. Assim, Vermeule enumera ao menos três possíveis erros doutrinários. O primeiro deles é o de se "fícar apenas filosofando", sem levar qualquer consideração acerca das instituições que se utilizarão dos preceitos que esse tipo de doutrina entende serem essenciais nas tomadas de decisão, como "democracia" ou "dignidade da pessoa humana", assim, nos termos do autor:

Filosofando completamente. Alguns teóricos tentam derivar um número de interpretações de premissas determinadamente não institucionais, conceitos particularmente de alto nível político como "democracia," "autoridade," ou "integridade," ou abstrações sobre o caráter legal da linguagem. (...) Apesar dessa espécie de análise parcial ser válida até aqui, eu devo arguir que essa não é possível usar a melhor análise para derivar a conclusões sobre específicos resultados ou doutrinas interpretativas, inexistindo número de considerações institucionais que sempre intervém entre premissas abstratas e conclusões concretas $^{24}$.

O segundo equívoco apontado por Vermeule é o do institucionalismo estilizado. Nesse segundo caso, os teóricos tratam sobre competências legislativas, judiciárias e executivas, mas em termos altamente abstratos, sem se preocupar se cada uma dessas instituições está realmente capacitada para realizar suas competências. $\mathrm{O}$ autor, nesse sentido, diz que:

Institucionalismo estilizado. Aqui os teóricos interpretativos falam sobre comparação entre competência institucional, mas de uma maneira estilizada e estereotipada, na base de visões abstratas de "legisladores," "agências," e "cortes". Nessa e em outras versões, o institucionalismo estilizado procede por fazer referência à pretensões conceituais sobre as características essenciais do legislativo, cortes, e agências, ao invés de fazer referência à pretensões empíricas sobre instituições em sistemas legais particulares ${ }^{25}$.

O terceiro erro é o do institucionalismo assimétrico. Esse está baseado no fato de se calcarem teorias nas melhores características de algumas instituições e nos piores erros de outras. Portanto, ao fazerem as comparações sobre quem deve ser o responsável final pelas tomadas de decisão, os teóricos acabam se baseando em um cenário errôneo, ou ao menos, incompleto, como afirma Vermeule:

\footnotetext{
${ }^{24}$ Vermeule Adrian. Judging Under Uncertainty: An Institutional Theory of Legal Interpretation. Harvard University Press, 2006, p. 16.

${ }^{25}$ Idem. p. 17
} 
Institucionalismo assimétrico. Um erro distinto, mas relato, é o de se tomar uma visão cínica ou pessimista sobre algumas instituições e uma injustificável visão otimista de outras. (...) O perigo aqui é o da falácia de um nirvana: uma análise pseudo-institucional que compare a pior visão de uma instituição e a melhor de outra $^{26}$.

Parece ser importante que o estudioso tente evitar esses erros diagnosticados por Vermeule. Se, como indicado inicialmente, aqueles que operam o direito tiveram um dia que sentar em cadeiras universitárias e aprender o conteúdo jurídico por meio de professores a melhoria da prática jurídica provavelmente virá (ainda que em marcha lenta) com alguns ajustes na prática acadêmica. A mudança de postura de uma jusfilosofia preocupada com justiça substancial por uma teoria que tenha em seu rol de interesses o bom funcionamento sistêmico parece ser de bom grado. Tão importante quanto decisões mais justas por parte das cortes deve ser a capacidade de seus julgados, e do direito em geral, de guiar habilmente novos futuros casos e condutas.

Por outro lado, a velocidade dessa transição pode ser acelerada se as instituições capacitadas ajudarem no processo. Sabe-se das imensas dificuldades de se inovar uma cultura. Mais ainda quando essa cultura tem base numa tradição. No entanto, é possível mudar e, nesse caso, não parece ser tão difícil. O Supremo e outros tribunais superiores podem, sim, esclarecer quais foram as classes de fatos relevantes para as decisões, e estabelecer em parâmetros gerais como devem ser entendidas questões no futuro. Eles têm a técnica, basta ver a capacidade de elaborar súmulas, precisa haver apenas uma mudança de entendimento sobre a importância de seus precedentes.

\section{BIBLIOGRAFIA}

ÁVILA, Humberto. Teoria dos Princípios - da definição à aplicação dos princípios jurídicos. $9^{\mathrm{a}}$ Edição. São Paulo: Malheiros, 2009.

CAVALCANTI, Arthur José Faravet. A Estrutura Lógica do Direito. Rio de Janeiro: Renovar, 2003.

MELlo, Patrícia Perrone Campos. Precedentes - $O$ desenvolvimento judicial do direito no constitucionalismo contemporâneo. Rio de Janeiro: Renovar, 2008

REALE, Miguel. Lições preliminares de direito. São Paulo: Saraiva, 2006.

SALOMÉ, Joana Faria. "A Teoria da Transcendência dos Motivos Determinantes no Supremo Tribunal Federal” In. Revista Forense, vol. 404, Julho-Agosto de 2009. p. 209-223.

SCHAUER, Frederick. Playing By the Rules: A Philosophical Examination of Rule-Based Decision-Making in Law and in Life. Oxford University Press, 1998.

- Thinking Like a Lawyer: A New Introduction to Legal Reasoning. Oxford University Press, 2009. 
STRUCHINER, Noel. "Indeterminação e Objetividade: Quando o Direito diz o que não queremos ouvir" In. Direito e Interpretação - Racionalidades e Instituições, São Paulo: Saraiva, 2011. p. 119-152.

. O Direito como um campo de escolhas: por uma leitura das regras prescritivas como relações. In. Nas fronteiras do formalismo. São Paulo: Saraiva, 2010. p. 103-127.

Direito e Linguagem: Uma Análise da Textura Aberta da Linguagem e sua Aplicação ao Direito. Rio de Janeiro: Renovar, 2002.

VERMEULE, Adrian. Judging Under Uncertainty: Na Institutional Theoryof Legal Interpretation. Harvard University Press, 2006.

\section{SÍTIOS VIRTUAIS}

http://www2.trf2.gov.br/NXT/gateway.dll?f=templates\&fn=default.htm\&vid=base_jud:v_sum http://www.tjrs.jus.br/site/jurisprudencia/sumulas/sumulas_do_tribunal_de_justica/

http://www.tjpr.jus.br/jurisprudencia-sumulas

http://www.tjce.jus.br/consultas/consultas_sumulas.asp

http://www.tjpb.jus.br/portal/page/portal/tj/home/consulta_sumulas?p_id=79

http://webfarm.tjrj.jus.br/biblioteca/asp/textos_main.asp?codigo=150637\&desc=ti\&servidor=1\&i Idioma $=0$

http://www.amb.com.br/docs/noticias/2010/CNJcriterio.pdf 